\title{
Сельское хозяйство и окружающая среда
}

\section{Н.В. Апатова, М.В. Быстрова, И.А Сумароков}

Рациональное природопользование особенно большое значение имеет для сельского хозяйства. Здесь очень четко проявляется связь между отдельными компонентами природы, и это необходимо учитывать как при развитии деятельности предприятий, так и частных домохозяйств. Земельная реформа, проводимая в Украине, привела к изменению структуры собственности в сельском хозяйстве. В настоящее время 66-68\% всей сельхозпродукции выпускается в частных хозяйствах, в то время как они занимают всего $15 \%$ площадей. За крупными, в основном государственными хозяйствами, по-прежнему остается $80 \%$ угодий. Эти данные свидетельствует о неэффективности использования земель государственными предприятиями, а следовательно, об ослаблении или отсутствия контроля над состоянием окружающей среды на огромных территориях. В то же время частный собственник, стремясь получить максимальную прибыль сегодня, редко задумывается о завтрашнем дне. К тому же контроль над многочисленными мелкими хозяйствами со стороны государства усложняется, что приводит к большему количеству различных нарушений. Эти проблемы сегодня очень актуальны и вопросы взаимодействия сельского хозяйства и окружающей среды, неотъемлемой частью которого оно само является, требуют детального рассмотрения.

Интенсивное развитие сельского хозяйства оказывает существенное влияние на окружающую среду, которое проявляется, в основном, в виде негативных экстерналий. Рост распаханности земельных угодий, увеличение парка тракторов и сельскохозяйственных машин, внесение большого количества органических и минеральных удобрений, применение средств защиты растений ведет к загрязнению почвы, водоемов и атмосферы вредными компонентами, химическими веществами, выхлопными газами.

Основными элементами в системе природопользования агропромышленного комплекса являются земельные, водные, лесные ресурсы, а также минеральное сырье. В единстве с живыми организмами (растениями, животными, микроорганизмами), климатом, рельефом, воздухом они образуют экологоэкономическую систему. В ней формируются необходимые условия для производства продукции, призванной удовлетворить потребности общества. Сегодняшнее сельское хозяйство значительно нарушило природную экологическую систему и способствовало созданию искусственной окружающей среды. Современное сельское хозяйство в основном энергоемкое, химикоемкое и оно требует интенсивного управления. Входные ресурсы сельского хозяйства - энергия и химикаты - получены из невозобновляемых, исчерпываемых природных ресурсов, таких как нефть и природный газ.

Традиционно экономисты анализируют влияние сельского хозяйства на окружающую среду в рамках экстерналий. Будем считать экстерналии, связанные с сельским хозяйством, только как отрицательные экстерналии, допуская, что им не соответствует ответного воздействия, т.е. что они односторонни.

Предположим, что существует всего два вида товаров: предлагаемые агропромышленным сектором А и не агропромышленным сектором В, которые включают в себя продукты промышленного производства и услуги окружающей среды. При таких обстоятельствах существует несколько отрицательных экстерналий, основными из которых являются следующие:

- отрицательное влияние одной части сельского хозяйства на другую его часть;

- отрицательное влияние сельскохозяйственного производства на другой сектор экономики;

- деятельность в несельскохозяйственном секторе может оказать отрицательное влияние на сельскохозяйственный сектор.

Рассмотрим подробно каждый из выделенных видов экстерналий.

Производства в одной отрасли сельского хозяйства могут иметь отрицательные экстерналии в других отраслях сельскохозяйственного производства. Такая деятельность включает использование некоторыми хозяйствами пестицидов (например, при разбрызгивании химикатов, брызги могут повредить урожай соседних хозяйств), использование азотных удобрений (например, когда в результате оказывается загрязненным водоем, который используется другими хозяйствами) или вырубка леса, которая может привести, например, к повышению водных горизонтов и засолению близлежащих почв. В результате на таких землях могут расти только наиболее устойчивые к засолению культуры. Вырубка деревьев может привести к повышению солености рек до такой степени, что их нельзя будет использовать для полива и питья домашнему скоту. Такие экстерналии засоления появились в ряде стран, например, в восточной Австралии, но также угрожают районам степного Крыма, где из-за неразумного орошения произошла избыточная минерализация и засоление почв.

В районах со значительным количеством осадков уничтожение естественной растительности в результате сельскохозяйственной деятельности обычно приводит к сильному оттоку воды. Растительность может быть уничтожена путем вырубки или культивации земель. В таких случаях в пойменных землях рек чаще случаются наводнения (паводки), которые происходят не только после сильных дождей, но и из-за эрозивных осадков (отложений), которые способствуют быстрому размыванию берегов рек. Рост таких наводнений оказывает отрицательное влияние на хозяйства, расположенные в низовьях рек, где почвы и пески становятся бесплодными в результате увеличения солевой эрозии. В более засушливых районах 
уничтожение растительности подвергает почвы ветровой эрозии. Почвы зерновых культур, вспаханные под пар, часто подвергаются значительному риску. Чрезмерный выпас скота также может спровоцировать ветровую эрозию. В результате хозяйства, расположенные вне областей действия ветровой эрозии, могут получить ущерб. Например, нежелательные частицы почвы и песка могут быть принесены на их территории, или урожайность понизится вследствие наличия в воздухе пыли.

В некоторых случаях в сельском хозяйстве существуют довольно прямые отрицательные влияния природных ресурсов, как в случае общего владения водными ресурсами. Представим, что речная вода используется для орошения несколькими хозяйствами. Если его спрос на воду превосходит имеющееся предложение, то возникает проблема распределения. При отсутствии контроля хозяйства, расположенные ниже по реке, будут получать количество воды, меньше необходимого. Следовательно, стоимость продукта, произведенного с помощью воды для орошения, для хозяйств нижнего течения реки будет выше, чем для хозяйств, расположенных выше по течению. Т.е. количество воды не распределено так, чтобы максимизировать стоимость своего вклада в производство. В этом случае общее количество воды должно быть распределено так, чтобы уравнять предельный продукт всех пользователей воды, необходимо подавать ограниченное количество воды как для хозяйств в верхней части реки, так и для хозяйств в нижней части реки. Проблема распределения водных ресурсов становится особенно острой для искусственных оросительных систем, связанных со строительством каналов и водоводов большой протяженности. Примером такого совместного пользования являются оросительные системы, созданные в степных районах Крыма на базе Северо-Крымского канала, требующего ежегодного содержания на функционирование и ремонт более 100 млн. гривен, в то время как урожайность на орошаемых землях падает из-за их минерализации, вымывания гумуса, заболачивания.

Политика по исправлению сложившейся ситуации может включать:

1. Обложение пользователей воды налогом, начисляемом на каждую единицу воды;

2. Продажа прав на использование общего количества доступной воды;

3. Представление рыночных квот на использование воды.

На практике непередаваемые квоты часто используются правительствами европейских стран для распределения прав пользования водой. Такая практика не всегда эффективна с экономической точки зрения, т.к. квоты редко распределяются таким образом, чтобы уравнять стоимость предельного продукта, полученного всеми пользователями воды.

С другой стороны, налоги и создание рынка воды могут также не быть оптимальными. Налоги должны устанавливаться, если спрос на воду или доступное количество воды изменилось, и это требует гибкого налогообложения и прогнозов.

Так как вода является важным и необходимым природным ресурсом для растущего населения и экономики, заслуживает рассмотрения другая связанная с сельским хозяйством проблема использования воды. Рассмотрим подземные воды или водное предложение. Это важный водный ресурс как для сельского хозяйства, так и для других областей. Природа этих вод различна, и поэтому рассмотренный здесь пример является частным случаем. Если к подземным водам имеется свободный доступ, то их использование вряд ли будет эффективным с точки зрения экономики.

Стоимость выкачивания или доступа к подземным водным бассейнам не может быть одинаковой для всех, кто занимается сельским хозяйством. При увеличении бесконтрольного выкачивания воды, уровень подземных вод может понизиться, и они будут недоступны на территориях, где подземные бассейны неглубоки. Иногда, это могут быть территории, которые используют воду более эффективно, или стоимость ее доставки на поверхность ниже. В результате политики свободного доступа к воде не только стоимость единицы воды возрастет, но также средняя стоимость (ценность) производства, использующего воду уменьшится.

Общее водоснабжение Крыма определяется, в том числе, состоянием артезианских подземных вод. С 1966 по 1980 год в степной части Крыма осуществлялся интенсивный водозабор подземных вод и при норме в 1086 тыс кубометров в сутки он фактически составлял 2164 тысячи кубометров (т.е. в 2 раза больше). В результате произошло объемное истощение и химическое загрязнение этих уникальных вод, являющихся единственным источником питьевой воды в этом регионе. Особенно тяжелая обстановка сложилась в Красноперекопском, Первомайском, Красногвардейском, Джанкойском, Раздольненском и Нижнегорском районах, где уровень подземных вод повысился с 30 до 11 метров, а их минерализация увеличилась до 1,5 - 8 гр на литр и вода уже не годится к использованию как питьевая. В среднем по всей протяженности Северо-Крымского канала грунтовые воды поднялись на 9 метров. В 2000 году дефицит пресной воды в степных районах Крыма составлял 60 млн. кубических метров. Само состояние артезианских скважин крайне неудовлетворительное (всего их 3020, из них для орошения используется 279).

Развитие искусственного орошения в Крыму привело к вымыванию растворимых солей из зоны аэрации и поступлению их в водоносные горизонты. Результат - засоление первого от поверхности эксплуатационного водоносного горизонта почти по все территории Первомайского, западной части Красногвардейского и Джанкойского, южной части Раздольненского, северной части Сакского районов. Эти местности лишились подземных вод питьевого качества.

Поскольку сельское хозяйство может отрицательно влиять на себя, оно может отрицательно влиять на другие сектора экономики и социальные интересы. Например, выделение нитратов из искусственных 
удобрений, используемых в сельском хозяйстве, или навоза животных, может загрязнить поверхностные или подземные воды, используемые человеком для питья, повлиять на качество воды, используемой в технических целях, способствовать росту сорняков в реках («задушить» их и повысить потери воды) и, в некоторых случаях, влиять на навигацию, и усиливать энтропию прудов и озер. Главным виновником ухудшения экологической ситуации в Черном море является постоянно возрастающее количество питательных веществ, попадающих в него различными путями. Так, только Дунай приносит ежегодно около 60000 тонн суммарного фосфора и 340000 тонн неорганического азота, половина которого поступает из сельскохозяйственных источников, а другая половина - как бытовые и промышленные отходы. Многочисленные береговые обитатели прямо сбрасывают свои сточные воды и другие отходы в море. Это приводит к чрезмерному увеличению фитопланктона и периодическому цветению морских водорослей.

В результате «переудобрения» Черного моря происходит уменьшение содержания кислорода, появление вирусов, смертельных для его обитателей. Возрастает количество осадков и растворимых в морской воде веществ, особенно органических, с 1960 года их стало в 2-3 раза больше. Наблюдается массовая смертность не только рыбы, но и моллюсков и ракообразных и структурное изменение популяций млекопитающих.

Уничтожение природной растительного покрова в целях сельского хозяйства может сделать ландшафты менее привлекательными для путешественников и туристов, хотя это не всегда так. Значительная изменчивость уровня воды в реках вследствие уничтожения естественной растительности, может негативно повлиять на доступность питьевой воды для городских территорий, усилить сезонные недостатки воды в городах и увеличить частоту городских наводнений. Большая мутность воды уменьшает популяции рыб, снижает число туристов, а на территориях, где недалеко от устьев рек растут кораллы, может привести к их уничтожению, т.к. во время наводнений грязные воды реки растекаются далеко в море. Накопление ила в гаванях и на водных путях увеличивает стоимость навигации. Увеличивающиеся паводки заливают дороги, которым наносится большой ущерб. Данный список может быть продолжен. В него входит также потеря диких видов животных из-за уничтожения мест их обитания. В прошлом использование в сельском хозяйстве некоторых ядов, таких как ДДТ, было неисправимо в смысле уничтожения дикой природы.

Поскольку сельское хозяйство может отрицательно влиять на другие сектора, они также могут отрицательно влиять на сельское хозяйство. Приведем несколько примеров.

Загрязнение воды промышленными производствами, добывающей промышленностью, городскими территориями может отрицательно влиять на сельское хозяйство. Посевы, политые «грязной» водой могут погибнуть или не дать должного урожая, домашний скот может отравиться, если выпьет воду из такого источника. Такие случаи в результате выброса химических отходов фабрик наблюдались в Китае.

Городские пользователи воды не могут полностью оценить стоимость, перекладываемую на сельское хозяйство, в результате уменьшения количества воды для сельскохозяйственных производств, горожане используют с экономической точки зрения чрезмерное количество воды.

При определенных условиях вырубка лесов может иметь негативные последствия для сельского хозяйства, например, увеличится затопляемость сельскохозяйственных земель. Урбанизация также может создать подобную проблему.

Загрязнение воздуха, и все что с ним связано, вызывает негативные последствия для сельского хозяйства. Выбросы с заводов по переработке свинца и тяжелых металлов, пыль из открытых шахт, загрязнения алюминиевых заводов, кислотные дожди, выбросы радиации - все это оказывает отрицательно влияние на сельскохозяйственное производство.

Для экономической политики, направленной на уменьшение экстерналий, не имеет значение причина их возникновения. Однако, стоимость проведения той или иной политики зависит от причин возникновения и природы экстерналий. Например, трудно установить налог для хозяйств за загрязнение нитратами, т.к. загрязнение происходит не одинаково и его сложно оценить.

В экономически развитых странах в течение последнего десятилетия происходит так называемая «зеленая революция», связанная с производством экологически чистого продовольствия и мероприятиями по охране окружающей среды. «Зеленая революция» включает биохимическую составляющую и, как правило, следит за состоянием окружающей среды и сельского хозяйства путем контроля использования химикатов, воды для орошения и сельскохозяйственной техники, использующей прямо или косвенно угольное топливо. Результатом «зеленой революции» явилось увеличение производительности сельскохозяйственных земель в развитых странах, а также она стала трамплином для развития некоторых стран. Более высокая производительность явилась следствием увеличения выращивания сразу нескольких культур, увеличение ответственности за использование искусственных удобрений, управление доступностью воды, контроль использования пестицидов для борьбы с сорняками и вредителями. Однако поднялся вопрос, является ли данная форма сельского хозяйства, которая сейчас преобладает в развитых странах, устойчивой. У ведущих экономистов не вызывает сомнений ее долгосрочная стабильность и высокая производительность. Однако увеличение выращивания нескольких культур приводит к ухудшению почв по следующим причинам:

- более частое возделывание земли приводит к ухудшению состояния почвы или ее структуры;

- уменьшается содержания органики и гумуса в почве из-за того, что очень малое количество органических отходов остается на полях и не происходит естественного увеличения количества этих веществ в почве (т.к. 
между периодами возделывания почвы произрастает очень малое количество травы и сорняков, а различные травы могут обеспечить определенное количество «зеленого удобрения»;

- увеличение почвенной эрозии, самого слоя почвы и ее плодородия вследствие частого возделывания;

- выращивание «зеленых удобрений» хотя бы на ранних стадиях «зеленой революции» оказывается экономически менее выгодным;

- смешанное сельское хозяйство может оказаться менее прибыльным;

- домашний скот, дающий природные удобрения, удаляется из окрестностей интенсивно возделываемых земель.

Химические удобрения также могут оказать долговременные нежелательные изменения в почве, т.е. увеличить содержание кислот и уменьшить значительное количество почвенной флоры и фауны. В период «зеленой революции» увеличилось использование искусственных пестицидов. Кроме отрицательного влияния на дикую природу, их использование приводит к неустойчивости производительности, т.к. сельскохозяйственные вредители становятся по отношению к ним все более устойчивыми.

Другое важное следствие «зеленой революции» и современного сельского хозяйства - это потеря генетического разнообразия. Зеленая революция обусловила то, что пропали многие виды культур, т.к. фермеры переключились на ограниченный круг улучшенных культур.

Сельское хозяйство, использующее органические удобрения, предлагается некоторыми социальными группами в качестве альтернативы современным биохимическим сельскохозяйственным системам. Главной причиной его продвижения являются лучшие последствия для здоровья и окружающей среды по сравнению с современным сельским хозяйством. Существуют доказательства, что органическое сельское хозяйство может давать большую прибыль, чем химическое, хотя процессы экономики и развития чрезмерно привержены химическому сельскому хозяйству. Причины для предубежденности по отношению к органическому сельскому хозяйству в ряде развитых стран включают: 1. Предоставление в недалеком прошлом субсидий для использования химикатов, в том числе и удобрений;

2. Относительная легкость патентования компаниями открытий и улучшений, связанных с химическим сельским хозяйством по сравнению с органическим сельским хозяйством; исследования в его области искажаются;

3. Продвижение и реклама неорганических методов ведения сельского хозяйства более велики;

4. Фермеры (а часто и производители сельскохозяйственных химикатов) не желают платить вообще или платить полную стоимость с учетом влияния на окружающую среду использования таких химикатов.

Экономическое развитие в целом поощряет рост химического сельского хозяйства, т.к. большее значение при этом приобретает стандартность продукта и стабильность его предложения. Возможно, рост рынков, специализация производства и стоимость перевозок, включают в бизнес, осуществляемый на большом расстоянии, дополнительную выгоду от стандартности и стабильности предложения. Покупателю сельскохозяйственной продукции в удаленном городе будет предложена одинаковая продукция, соответствующая определенным стандартам. Сегодня супермаркеты делают большую надбавку за стандартность розничной продукции.

Другой причиной уменьшения сферы органического сельского хозяйства в некоторых странах является развитие урбанизации. Органические вещества, отправляемые из села в город редко возвращаются обратно для использования в сельском хозяйстве. В таких странах как Китай, где нечистоты традиционно используются как удобрения, городские сточные воды редко используются для этих целей. Это происходит по двум причинам:

- стоимость сбора и транспортировки органических отходов в сельскую местность высока;

- городские органические отходы часто содержат вещества, губительные для сельского хозяйства.

Таким образом, в результате урбанизации органические отходы теряются для сельского хозяйства, а города сбрасывают отходы в воду. Также городские жители в основном не представляют себе полную стоимость захоронения и утилизации отходов, что в целом не поощряет производство отходов для органического использования.

Органические и не химические системы сельского хозяйства значительно отличаются друг от друга по уровням дохода. С точки зрения отсутствия отрицательных экстерналий и устойчивости дохода органические системы приобретают все большую актуальность. Даже если система не является полностью органической, меньшее использование химикатов и вовлечение органических и природных методов дает экологические преимущества. К не химической системе относится форма смешанного сельского хозяйства, основанная на совместном выращивании многолетних растений, таких как фруктовые деревья и кусты, включающая также выращивание некоторых однолетних и двулетних растений, сельскохозяйственных животных для возобновления питательных веществ, контроль за сельскохозяйственными вредителями т.д. Она используется для создания жизненного сообщества животных и растений, необходимых для потребления людям, создающим замкнутое сообщество. В идеале она включает смешанное сельское хозяйство, устойчивую интегрированную систему или экологическое сообщество, разнообразие и само равновесие, а также самодостаточность, для которой необходимо лишь несколько внешних ресурсов. Несмотря на то, что смешанная форма сельскохозяйственного производства имеет стабильную производительность и обладает экологическими преимуществами по сравнению с 
современными системами сельского хозяйства, она подходит небольшим сообществам в такой экономической ситуации, когда не требуется продукта в больших количествах, специализированного для рынка, и подлежащего перевозке на большие расстояния. Смешанная форма сельскохозяйственного производства подходит для небольших групп людей, например, группам альтернативного стиля жизни на западе. Она также может быть полезной для самодостаточных обществ, которые еще существуют в развитых странах.

Важным вопросом взаимодействия сельского хозяйства и окружающей среды является сохранение разнообразия видов животного и растительного мира, в том числе и сохранение дикой природы. Хотя сельское хозяйство сохраняет некоторые виды, которые были бы подвержены вымиранию вследствие вторжения человека, охоты на них, но в то же время сельское хозяйство значительно повлияло на уменьшение видового разнообразия, в основном путем разрушения мест обитания растений и животных. Сельское хозяйство часто является предшественником изменений окружающей среды, к которым также относится создание городских территорий.

Современные системы сельского хозяйства уменьшают разнообразие видов, т.к. часто создают контролируемую окружающую микро среду. Соответственно появляются одинаковые контролируемые окружающие микро среды. В таких средах выращивается одна или несколько культур, дающих максимально возможную прибыль. С развитием сельского хозяйства и «зеленой революцией» число видов каждого растения и домашних животных заметно сократилось, что уменьшило также генофонд, доступный сельскому хозяйству.

Локальная или частная экономическая эффективность современного сельского хозяйства требует специализации, а следовательно и уничтожения некоторых природных препятствий для сельскохозяйственных машин. Таким образом, часто уничтожаются деревья и кусты, чтобы было проще использовать тракторы и другие машины, а в Европе уничтожено много живых изгородей для создания больших полей, которые более дешево обрабатывать большими тракторами и машинами. Для возможности использования сельскохозяйственной техники на некоторых территориях были разрушены пруды или осушены болота. Такие действия вредно влияют на популяции диких видов. Потеря прудов и болот может отрицательно сказаться на мигрирующих и болотных птицах. Осушение земель, затопленных морем, отрицательно сказывается на разведении рыб, т.к. такие участки часто являются питомниками для рыб.

В результате такого влияния на дикую природу, расширяется контроль за сельскохозяйственной деятельностью и ее развитием. В некоторых странах и штатах введены ограничения на изменения мест обитания растений и животных на территориях частных хозяйств. Например, вырубка леса может быть запрещена или разрешена только в случае, когда специальный экологический суд взвесит все за и против подобных изменений окружающей среды. Регулирование вырубки деревьев особенно важно, т.к их уничтожение отрицательно влияет в целом на окружающую среду и сказывается на выживании отдельных видов. Вырубка деревьев приводит к росту эрозии, более быстрому стоку воду, а значит затоплению и другим гидрологическим эффектам в нижних течениях реки, а также к засолению земель на прилежащих территориях. Вырубка может контролироваться набором альтернативных политических инструментов. Это специальные налоги на вырубку, продажа прав на такую деятельность и субсидии за сохранение деревьев. Но эти меры не учитывают разницу между территориями, где проводится вырубка, различными видов деревьев, которые могут приносить как пользу, так и вред. Одинаковы меры более просты для управления, они оптимальны только в том случае, когда экстерналии не зависят от месторасположения и вида деревьев. На территориях, где экстерналии зависят от указанных условий, надо сочетать административные меры с экономическими.

Подобный вопрос должен быть рассмотрен и в отношении земель, которые используются для многих целей, включая социальные и экологические. Возможно, социальные цели подразумевают заключение договора между хозяйствами или их частями о защите дикой природы, например, сохранения мест обитания диких видов. Так желтоглазый пингвин сейчас является довольно редким видом в Новой Зеландии. Одной из главных причин уменьшения их популяции явилось потеря прибрежных мест обитания, в основном из-за вырубки прибрежных лесов для нужд сельского хозяйства, что привело к уменьшению высокого растительного покрова. Сохранение этого вида можно обеспечить, выделив относительно небольшую территорию для жизни пингвинов с малыми потерями для сельского хозяйства, создание заповедника. В таких случаях может быть заключено соглашение, ограничивающее использование земли. При немедленном ограничении использования земли может быть выплачена компенсация собственникам земли. Другим интересным примером является управление численностью популяции кенгуру, а также много других.

Связанный с вышеизложенными фактами вопрос касается разрешения доступа широкому кругу людей на обрабатываемые земли с рекреационными целями. В Британии пешеходные дорожки часто проложены по обрабатываемым землям, что делает доступной рекреацию на открытом воздухе. Также, в многих местах пользуются успехом сельские праздники, которые предполагают отдых на воздухе, и способствуют сохранению природы.

Обобщая вышесказанное можно сделать вывод, что сельское хозяйство является с одной стороны причиной значительных экологических потерь, а с другой - потенциальной выгоды от сохранения дикой 
природы и поддержания жизнеобеспечивающих систем. Поэтому оно является центральным в экономике охраны окружающей среды.

Стабильное экономическое развитие и поддержание видового разнообразия - это главные вопросы для сохранения окружающей среды. Значение сельскохозяйственных систем для стабильности производительности сельского хозяйства и его влияние на видовое разнообразие позволяет понять концепцию устойчивого развития.

\section{Литература}

1. M. Janssen. Modelling Global Change. The art of integrated assessment modelling. USA, E.Elgar, 1998.

2. C. Perrings. Economics of ecological resources. Selected Essays. USA, E.Elgar, 1996.

3. J.C.M. van der Bergh, J. van der Straaten/ Economy adn Ecosystems in Change. USA, E.Elgar, 1997.

C. A. Tisdell. Economics of Environmental Conservation. Elsevier, 1994. 